Gerión. Revista de Historia Antigua

ISSN: 0213-0181

\title{
El estatus legal del liberto municipal
}

\author{
Nina Spichenko ${ }^{1}$
}

Recibido: 28 de marzo de 2018 / Aceptado: 14 de julio de 2018

Resumen. La comunicación se centra en el estatus legal de los libertos municipales en el período imperial. Según la rúbrica 72 de la lex Irnitana el servus publicus manumitido adquiría una doble condición: era Latinus y municeps. La paradoja del estatus del liberto municipal, que era ciudadano de la comunidad, pero no tenía pleno derecho, se analiza aquí a la luz de una serie de documentos jurídicos. La naturaleza doble del liberto municipal está ligada al procedimiento de la manumisión, en la cual el magistrado no usaba la vindicta, y a la naturaleza del patrono, es decir, el municipium, que manumitía a su esclavo sólo otorgándole el estatus de otros ciudadanos suyos. Para los munícipes el liberto municipal era un munícipe que tenía, como todos sus conciudadanos, el poder de petición de herencia (hereditas) y el de posesión de los bienes hereditarios (bonorum possessio); pero para el municipio, era un liberto latino juniano, cuyos bienes el municipio podía, como patrono, pretender después de su muerte.

Palabras clave: latinus; municeps; manumissio vindicta; hereditas; bonorum possessio.

\section{[en] Legal Status of a Municipal Freedman}

\begin{abstract}
This paper centres on the legal status of municipal freedmen in the Imperial period. It is known from chapter 72 of the Lex Irnitana that emancipated servus publicus received double status: that of Latinus and that of municeps. The paradox of municipal freedman being a citizen of his community but not enjoying full rights is reconsidered in the light of a series of legal documents. The double nature of municipal freedmen was connected, firstly, with the procedure of manumission, when the magistrate could not use vindicta, and, secondly, with the nature of the patron, i.e. municipium, which could emancipate its slave only to receive the status of its other citizens. For the municipals a freed servus publicus became a municipal enjoying, as well as the rest of the citizens, the right of hereditas and bonorum possessio; but for the municipium he was a Latinus Iunianus, his patron having the right to his legacy.
\end{abstract}

Keywords: latinus; municeps; manumissio vindicta; hereditas; bonorum possessio.

Sumario. 1. Introducción. 2. El estatus personal de los libertos públicos en los documentos jurídicos. 3. ¿Se realizaba por vindicta la manumisión del servus publicus? 4. Servus publicus es la posesión del municipio. 5. Hereditas y bonorum possessio del munícipe-latino juniano. 6. ¿Por qué la manumisión del servus publicus se realiza sin vindicta? 7. Conclusión. 8. Referencias bibliográficas.

Cómo citar: Spichenko, N. (2018): El estatus legal del liberto municipal, en Gerión 36/2, 611-625.

1 State Academic University for the Humanities (GAUGN), Moscú.

E-mail: politology@gaugn.ru 


\section{Introducción ${ }^{2}$}

El problema del estatus legal de los libertos municipales de la época del Imperio Romano no se plantea con frecuencia en la historiografía, sino que la atención de los investigadores, las más de las veces, se concentra en la cuestión del estatus de los esclavos públicos y no en la de su condición legal después de su manumisión.

Poco sabemos del estatus legal de los libertos públicos, lo que se explica, ante todo, por la ausencia de fuentes que podrían dar información directa sobre este estatus.

Se suele pensar que el estatus de los libertos públicos es igual al estatus de los libertos de pleno derecho, manumitidos vindicta, que se hacían ciudadanos romanos (cives Romani).

El primero que puso en duda que los esclavos públicos, una vez manumitidos, fuesen libertos de pleno derecho, es decir cives Romani, fue Leon Halkin. ${ }^{3}$ Según su opinión los servi publici de los municipios no eran manumitidos ni por la vindicta, ni por el censo, ni por el testamento, sino que se convertían en Latini Iuniani. Pero su punto de vista sobre el estatus legal de los libertos municipales no encontró apoyo en las obras dedicadas a la historia de los esclavos públicos.

Walter Eder, al investigar el procedimiento de la manumisión del servus publicus antes del descubrimiento de la ley Irnitana, siguió la opinión común: la forma de manumisión del esclavo público había sido tomada completamente del derecho privado y de ahí se sigue que el servus publicus era manumitido como un esclavo privado, es decir vindicta, y se hacía así liberto de pleno derecho. ${ }^{4}$

En la obra más reciente sobre los esclavos y libertos públicos, escrita por Françoise Sudi-Guiral, no se estudian en absoluto los aspectos legales referidos al procedimiento de manumisión del esclavo público ni tampoco a la condición del liberto público. $^{5}$

El descubrimiento de la lex Irnitana, con su rúbrica 72 dedicada a la manumisión de los esclavos públicos, permitió plantear la cuestión del estatus legal de estos libertos.

[72] R(ubrica) de servis publicis manumittendis.

Si quis duovir i(ure) d(icundo) servum publicum servamve publicam manumittere volet is de eo deve ea ad decuriones conscriptosve cum duae partes non minus decurionum conscriptorumve aderunt referto censeantne eum eam \{q\} ve manumitti si e(or)um qui aderunt non minus duae partes manumitti censuerint et si is eave eam pecuniam quam decuriones ab eo eave accipi censuerint in publicum municipibus municipi(i) Flavi Irnitani dederit solverit satisve fecerit tum \{i\}is IIvir\{is\} $i($ ure $)+d$ (icundo) eum servom eamve servam manumittito liberum liberamve esse

2 Ante todo me gustaría agradecer cordialmente a Estela Beatriz García Fernández, Profesora Titular de Historia Antigua de la Universidad Complutense de Madrid, y a Pedro López Barja de Quiroga, Profesor Titular de Historia Antigua de la Universidad de Santiago de Compostela, los organizadores de la "Reunión científica sobre la condición / ciudadanía latina", su amable invitación a participar en el citado coloquio. Aparte quisiera expresar mi más sincera gratitud a Pedro López Barja de Quiroga por la revisión del estilo de mi comunicación, sus preguntas y sugerencias, que me han ayudado a redactar la versión final de este artículo.

Halkin 1897, 142-143.

Eder 1980, 114-122.

Sudi-Guiral 2013. 
iubeto qui ita manumissus liberve esse iussus erit liber et Latinus esto quaeve ita manumissa liberave esse iussa erit libera et Latina esto eiusque municipes municipi(i) Flavi Irnitani sunto neve quis ab is amplius quam quod decuriones censuerint ob libertatem capito neve facito quo quis ob eam rem eove nomine quid capiat inque eius qui ita manumissus manumissave erit hereditate\{m\} bonorum possessione petenda operis dono munere idem iu\{ri\}s municipi(i) Flavi Irnitani esto quod esset si municipi(i) Italiae libertus liberta esset qui adversus ea quid fecerit sciens d(olo) m(alo) is quanti ea res erit tantum in publicum municipibus municipi(i) Flavi Irnitani d(are) d(amnas) esto eiusque pecuniae deque ea pecunia municipi eius municipi(i) qui volet cuique per h(anc) l(egem) licebit actio petitio persecutio esto. ${ }^{6}$

Antes de que empecemos a analizar esta rúbrica, vamos a referir aquellos puntos de vista que han sido expuestos por los investigadores sobre la manumisión del esclavo público según la lex Irnitana.

La primera publicación dedicada a la manumisión del servus publicus apareció inmediatamente después del descubrimiento de la ley Irnitana.

Teresa Giménez-Candela señaló que, si bien en la rúbrica 72 no se menciona la vindicta en el procedimiento de la manumisión de servus publicus, ése era el procedimiento que se utilizaba con los esclavos municipales. ${ }^{7} \mathrm{Su}$ afirmación se basa en el estatus que los libertos municipales recibían junto con la libertad según la fórmula que pronunciaba el duovir durante la manumisión: liber et Latinus $<\ldots$. $>$ libera et Latina $<\ldots>$ eiusque municipes municipi Flavi Irnitani sunto. En su opinión todos los ciudadanos del municipio de Irni nacidos libres, que no eran cives Romani, eran latinos, es decir los beneficiarios de ius Latii. ${ }^{8}$

Alvaro D’Ors, frente a la opinión de Giménez-Candela sobre la manumissio vindicta del esclavo público, señaló, por su parte, que en la ley Irnitana no se decía nada sobre aquel procedimiento y que la manumisión del esclavo público muy probablemente no se hacía mediante vindicta, sino por una declaración pública que hacía el magistrado proclamando libre al esclavo en presencia del ordo decurionum. Con todo, Álvaro D’Ors no concluyó de eso que el esclavo público manumitido de esta manera se convirtiera en latino juniano. Según su opinión, el otorgamiento al liberto municipal de hereditas y bonorum possessio significaba conceder el ius Latii al nuevo ciudadano del municipio latino. ${ }^{9}$

Julián González y Michael Crawford también insistieron en que al liberto municipal, junto con la libertad, se le otorgaban los privilegios del ius Latii y no el estatus del latino juniano. ${ }^{10}$

Hay que notar que los autores de los primeros comentarios sobre la rúbrica 72, intentando interpretar los estatus del liberto como latinus y municeps, en sus razonamientos se fundan en la rúbrica 28 de la ley Irnitana y la ley Salpensana sobre la manumisión del esclavo privado que pertenecía a un munícipe latino.

\footnotetext{
6 El texto de la rúbrica 72 de la ley Irnitana se cita por la edición de González Fernández - Crawford 1986, 147 243. 
Gracias a la ley Salpensana, el contenido de la rúbrica 28 era conocido mucho antes del descubrimiento de la ley Irnitana, por eso el municeps (...) qui Latinus erit siempre se entendía como el munícipe beneficiario de ius Latii.

Este punto de vista se funda ante todo en el testimonio de Plinio el Viejo sobre el otorgamiento por Vespasiano del ius Latii a toda Hispania en los años 73-74 d.C. ${ }^{11}$

Mientras tanto, un poco antes del descubrimiento de la ley Irnitana, Fergus Millar sugiere que la rúbrica 28 de la ley Salpensana trata sobre la manumisión del esclavo de un latino juniano y no de un beneficiario del ius Latii. Su opinión se basa en la observación de que en las fuentes jurídicas de la época imperial, ante todo en las Instituciones de Gayo, se les daba el nombre de latinos tan sólo a los libertos - Latini Iuniani, y las leyes municipales de Salpensa y de Malaca no podían contradecir la terminología jurídica contemporánea y generalmente aceptada en todo el Imperio. Millar concluyó que los libertos Latini Iuniani no se distinguían de los libertos ciudadanos romanos, porque también tenían derecho de manumitir a sus esclavos y eran munícipes, así como lo eran los libertos de pleno derecho manumitidos vindicta. ${ }^{12}$

Su hipótesis de que los latinos junianos eran incorporados en los municipios y se beneficiaban de los derechos de los ciudadanos romanos al igual que los libertos de pleno derecho, encontró una crítica muy argumentada por parte de Michel Humbert, especialmente en lo que se refería a la incorporación completa de los latinos junianos en el municipio incluyendo el derecho de manumitir a los esclavos. ${ }^{13}$ Con todo, Humbert aceptó el punto de vista de Millar de que las fuentes epigráficas jurídicas no daban el nombre de Latini a quienes se beneficiaban del ius Latii. ${ }^{14}$ Pero el investigador francés, convencido de que los latinos junianos carecían de derechos civiles y, en general, de ciudadanía, admitió que en el terreno provincial, en las leyes municipales de Salpensa y Malaca, el concepto Latini podía aplicarse a los beneficiarios de ius Latii. ${ }^{15}$

En general se puede constatar, que los investigadores que se especializan en el estatus personal de los munícipes de los municipios Flavios que no eran cives Romani, se encuentran ante el dilema siguiente: determinar si el ius Latii es un derecho personal, que se puede definir como una ciudadanía especial, alternativa a la ciudadanía romana, o bien si es un derecho colectivo que se otorgaba a una comunidad peregrina, según el cual era posible adquirir la ciudadanía romana mediante el desempeño, durante un año, de los cargos municipales (ius adipiscendae civitatis per magistratum). ${ }^{16}$

Heidrun Schulze-Oben, investigando el estatus legal de los libertos municipales de Irni, piensa que estos libertos recibían por la manumisión el estatus de munícipe junto con el de un latino libre, beneficiario de ius Latii. Según la opinión de esta investigadora, los libertos municipales no podían ser Latini Iuniani siendo manumitidos por el municipio latino (municipium Latinum), cuyos ciudadanos eran cives Latini, y por tener hereditas que era característica de un liberto de pleno derecho y no del latino juniano. ${ }^{17}$

Andrew T. Fear apoyó en principio la hipótesis de Millar, basándose en la frase de la rúbrica 72 de la ley Irnitana: liber et Latinus $<\ldots>$ libera et Latina $<\ldots>$

11 Plin. HN 3.30: Universae Hispaniae Vespasianus Imperator Augustus iactatum procellis rei publicae Latium tribuit.

Millar 1992, 630-631.

Humbert 1981, 209-216.

Humbert 1981, 221.

Humbert 1981, 222.

Braunert 1966, 68-83; Millar 1992, 630-631; Humbert 1981, 221-222.

Schulze-Oben 1989, 42. 
eiusque municipes municipi Flavi Irnitani sunto ${ }^{18}$ Pero poco más tarde cambió de opinión e interpretó ius Latii como el derecho privado con los poderes de manus, mancipium y patria potestas del que se beneficiaban los cives Latini. ${ }^{19}$

Pedro López Barja de Quiroga, analizando el estatus de los libertos municipales, según la rúbrica 72, supone que éstos no podían ser Latini Iuniani, sino que se convertían en latinos beneficiarios de ius Latii ${ }^{20}$ Arnold Kränzlein también sugirió que los libertos municipales se hacían munícipes y latinos beneficiarios de los privilegios de ius Latii ${ }^{21}$ Según Wolfgang Dieter Lebek los esclavos públicos por su manumisión recibían el estatus del municeps Latinus con los derechos de los beneficiarios del ius Latii y se denominaban Latini por el estatus del municipio que aparece designado una vez en la rúbrica 30 de la ley Irnitana como municipium Latinum. ${ }^{22}$

Mientras tanto, la idea de Millar encontró un sólido apoyo en las obras de Patrick Le Roux. Basándose en la idea formulada por Humbert de que todo municipio era un conjunto de ciudadanos romanos, Le Roux insiste en que el munícipe del municipio Flavio es un ciudadano romano. ${ }^{23}$ Además advierte que la ley Irnitana conoce sólo un estatus civil, el de municeps, pero dentro de este estatus general cada persona tenía su estatus personal que dependía de su origen. ${ }^{24}$ Postula que los latinos junianos estaban incorporados en los municipios, tenían la propiedad y en algunos casos podían conseguir la civitas Romana. Más tarde, bajo la presión de la crítica, Le Roux dejó de insistir en que los libertos municipales eran latinos junianos. Al analizar los datos relativos a la onomástica de los libertos municipales, que recibían nombres gentilicios como Publicius y Flavius, notó que estos libertos pertenecían tanto a los ciudadanos romanos como a las civitates. ${ }^{25}$

Según la opinión de Jane F. Gardner, desde el punto de vista de los ciudadanos romanos, el liberto público era latino juniano, y desde el punto de vista de los conciudadanos del municipio era munícipe con los mismos derechos que tenían otros munícipes. El hecho de que la ley le obligase a restituir sus bienes a su patrono, es decir, al ordo decurionum, demuestra su condición de latino juniano; en cambio el que la ley le permita manumitir a su esclavo vindicta en la presencia del magistrado, demuestra su condición de munícipe. Gardner supone que esta práctica de la manumisión en dos condiciones era habitual en las provincias, donde la mayoría de la población eran peregrinos y donde la legislación municipal tenía un carácter experimental. ${ }^{26}$

Consideramos que la respuesta a la cuestión del estatus legal del municeps Latinus hay que buscarla en los documentos jurídicos romanos dedicados a la condición de los libertos municipales, y hacerlo independientemente de la discusión sobre el otorgamiento de ius Latii a las comunidades peregrinas y su promoción al estatus de los municipios.

Señalemos tres posiciones básicas en las que nos fundamos en nuestra investigación de los problemas planteados.

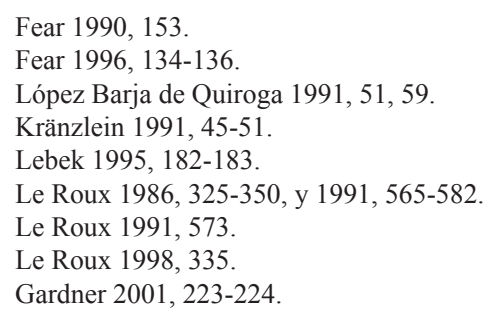


Primero. Ius Latii no es un derecho personal que se puede definir como una ciudadanía especial, alternativa a la ciudadanía romana. ${ }^{27}$ Ius Latii es un derecho colectivo que se otorgaba a una comunidad peregrina, según el cual era posible adquirir la ciudadanía romana mediante el desempeño, durante un año, de los cargos municipales (ius adipiscendae civitatis per magistratum).

Segundo. El municipio, independientemente de su nominación y del momento histórico - municipium Latinum, municipium Flavium, municipium Italiae-, siempre ha sido una comunidad de ciudadanos romanos, es decir municipium civium Romanorum.

Tercero. En los textos jurídicos de la época del Imperio Romano se denominan Latini tan sólo los libertos, y nunca los beneficiarios del ius Latii.

\section{El estatus personal de los libertos públicos en los documentos jurídicos}

En la historiografía dedicada a los latinos junianos encontramos un resistente estereotipo sobre su origen. Estos libertos siempre se conciben como esclavos que eran posesión privada y fueron manumitidos por su dueño sin las formalidades jurídicas, es decir inter amicos (entre amigos), y no por vindicta, por censo o por testamento, o bien que fueron liberados mediante el procedimiento formal, pero siendo ellos menores de treinta años.

Pero nada nos impide suponer que el estatus del latino juniano se aplicaba tanto a los libertos de los esclavos privados como a los libertos municipales.

En actualidad disponemos sólo de dos fuentes de la época imperial que nombran explícitamente clases de libertos municipales: es el fragmento 7.9.3 del Código de Justiniano y la rúbrica 72 de la ley Irnitana.

Comparemos dos fuentes jurídicas independientes que mencionan a los libertos municipales. Primero examinemos el testimonio que habla directamente del estatus personal del liberto municipal.

Titulo non praecedente, quibus dominia servorum quaeri solent, municipum libertus servus non efficitur. Si itaque secundum legem vetti libici (Vectibulici?), cuius potestatem senatus consulto Iuventio Celso iterum et Neratio Marcello consulibus facto ad provincias porrectam constitit, manumissus civitatem Romanam consecutus es, post vero ut libertus tabularium administrando libertatem quam fueras consecutus non amisisti, nec actus tuus filio ex liberis ingenuo suscepto, quominus decurio esse possit, obfuit. ${ }^{28}$

27 Según mi opinión en la conocida frase incolae, qui cives R(omani) Latinive cives erunt (Lex Malacitana, cap. 53) los conceptos cives Romani y Latini cives son cosas diferentes. No debemos cambiar de lugar las palabras Latini y cives porque así transformamos radicalmente el concepto. En el caso de cives R(omani) la palabra Romani es adjetivo, en cambio en el caso de Latinive cives la palabra Latini es sustantivo, lo que marca la partícula -ve. Suponemos que estos Latini cives eran los latinos junianos que tenían otra origo es decir eran ciudadanos de otras comunidades (por ejemplo de otros municipios), lo que indica en su caso el concepto cives, y que se mudaron de su comunidad natal a otro municipio que eligieron como su domicilio. Sobre el tema de las interpretaciones del concepto Latini cives ver: Mommsen 1905, 303-304, y 1887, 611; Braunert, 1966, 75; Galsterer 1971, 39; Millar 1992, 633; Wolff 1976, 276-277; Humbert 1981, 216-217; Chastagnol 1995, 136; Le Roux 1991, 568, y 1998, 323; Gardner 2001, 225.

28 C.Iust. 7.9.3. 
Este fragmento nos informa de que el liberto municipal podía adquirir la ciudadanía romana en virtud de la así llamada lex vetti libici.

En este texto, así como en la rúbrica 72 de la ley Irnitana, el estatus personal de los libertos municipales está redactado con precisión: la ley Irnitana declara que el liberto es libre y latino: liber et Latinus esto; y el rescripto de Diocleciano y Maximiano dirigido a Filadelfo dice que el esclavo municipal, después de la manumisión, consigue la ciudadanía romana: manumissus civitatem Romanam consecutus es.

Los juristas clasifican a los libertos en tres categorías: ciudadanos romanos, latinos-junianos y aquellos que son "de los súbditos" (dediticii), independientemente de si estos libertos fueron manumitidos de los esclavos privados o públicos. ${ }^{29}$

El texto de la rúbrica 72 de la ley Irnitana y el texto del fragmento 7.9.3 del Código de Justiniano no contradicen las palabras de Gayo y Ulpiano, sino que dejan ver claro que entre los libertos municipales podían estar tanto los latinos junianos como aquellos que consiguieron la ciudadanía romana. Hay que subrayar que Lex Irnitana es el primer documento jurídico romano conocido en el presente, que dice expresa y claramente que el municipio - la comunidad romana- manumite a su esclavo (servus publicus) otorgándole el estatus del latino juniano y el del munícipe a un mismo tiempo.

A continuación nos queda por ver cómo, mediante el procedimiento de la manumisión, el servus publicus obtiene dos estatus, que suelen considerarse mutuamente excluyentes: el estatus del latino juniano y el estatus del munícipe, y por qué razón aparece el estatus dual del liberto público.

\section{3. ¿Se realizaba vindicta la manumisión del servus publicus?}

Giménez-Candela ${ }^{30}$ y Schulze-Oben ${ }^{31}$ piensan que la manumisión del servus publicus del municipio Flavio Irnitano se realizaba por vindicta. Sin embargo, el texto de la rúbrica 72 no lo menciona para nada.

Como ya hemos dicho, el procedimiento de la manumisión del esclavo público se llevaba a cabo por el duovir iure dicundo.

En el Código de Justiniano, en el título De vindicta libertate et apud consilium manumissione, hay un rescripto de Diocleciano y de Maximiano dirigido a una tal Attia, que dice lo siguiente: Nec mulierem per maritum nec alium per procuratorem vindicta manumittere posse non est ambigui iuris. ${ }^{32}$

Ya en su tiempo León Halkin notó que en este fragmento, si lo situamos en el contexto de todo el título, se trata sobre la imposibilidad de conceder al esclavo la libertad vindicta por un apoderado. El investigador concluye que como era imposible manumitir vindicta mediante un apoderado de la comunidad, este esclavo no se hacía un liberto ciudadano romano sino un latino juniano. Halkin llamó la atención sobre la imposibilidad de manumitir a un esclavo vindicta por un magistrado en presencia del consejo municipal, por lo cual tal esclavo se convertía en latino juniano. ${ }^{33}$

29 Gai. Inst. 1.12: Rursus libertinorum genera sunt tria: aut enim cives Romani aut Latini aut dediticiorum numero sunt. Ulp. 1.5: Libertorum genera sunt tria, cives Romani, Latini Iuniani, dediticiorum numero.

30 Giménez-Candela 1981, 50.

31 Schulze-Oben 1989, 41.

32 C.Iust. 7.1.3.

33 Halkin 1897, 142. 
Teniendo en cuenta estas consideraciones importantes de León Halkin, proponemos nuestra interpretación de este texto que merece un análisis detallado y puede dar respuesta a la pregunta de si el duovir iure dicundo usaba vindicta durante la manumisión del esclavo público.

En el rescripto de Diocleciano, ${ }^{34}$ dado como respuesta a una contienda, se examinan dos hipótesis que tienen en común la conclusión de que no cabe ninguna duda jurídica -non est ambigui iuris-de que la mujer no puede manumitir vindicta por su marido -nec mulierem per maritum (...) vindicta manumittere posse-y de que nadie puede hacerlo por un apoderado -nec alium per procuratorem vindicta manumittere posse-.

Es probable que ambos ejemplos no fueran unidos casualmente. Si consideramos todo el texto del rescripto entenderemos por qué el magistrado municipal no podía conceder la libertad al esclavo público por vindicta.

Si quería manumitir personalmente a su esclavo vindicta tenía que actuar como una persona privada y no como un funcionario, es decir, tenía que actuar como cualquier ciudadano y conceder libertad a su esclavo vindicta en presencia del magistrado, y no declararlo libre mediante el uso de su cargo oficial.

Una de dos: o actúa como un funcionario y se ocupa de los asuntos de otras personas privadas que tienen intención de manumitir a sus esclavos, o actúa él mismo como una persona privada y manumite a su esclavo en presencia de otro funcionario con facultades judiciales. Estas consideraciones nos sugieren la respuesta a la pregunta, por qué en la rúbrica 72 de la ley Irnitana no se dice nada sobre manumissio vindicta durante el procedimiento de la manumisión del esclavo público.

El duovir iure dicundo del municipio Flavio Irnitano no podía manumitir el esclavo porque actuaba como funcionario y no como una persona privada. No manumitía a su propio esclavo sino a un esclavo público. No podía actuar como un ciudadano que concediese la libertad a su propio esclavo, o sea un esclavo privado, sino que, en este caso, representaba los intereses de otro dueño, que era el municipio.

Estas consideraciones hacen el texto de la rúbrica 72 más fácil de entender: el duovir manumitía servus publicus sin usar vindicta. La ley Irnitana no dice que la manumisión se hiciera vindicta: según el texto, el duovir presenta una propuesta al ordo decurionum sobre la manumisión del esclavo público (duovir ... ad decuriones conscriptosve ... referto) y recibiendo la aprobación de la mayor parte de los presentes (non minus duae partes manumitti censuerint), concede la libertad a tal esclavo o esclava (eum servom eamve servam manumittito) y les ordena ser libres (liberum liberamve esse iubeto).

Parece que el procedimiento era como estaba prescrito por la ley: anunciaban que el esclavo obtenía libertad y le ordenaban ser libre, sin aplicar cualesquiera otras formalidades, es decir sin vindicta. El texto no tiene ningún significado implícito relativo al procedimiento de manumissio vindicta, la ley Irnitana nada oculta y nada calla.

\section{Servus publicus es la posesión del municipio}

En su tiempo Halkin prestó atención al hecho de que el esclavo público estaba en posesión de la comunidad y no de sus ciudadanos. Este hecho, aceptado por todos

34 C.Iust. 7.1 .3 
los investigadores y nunca puesto en duda por nadie, no ha sido analizado profundamente. ${ }^{35}$

Mientras tanto el análisis del trato que recibía el esclavo público por parte de la comunidad, en tanto que posesión colectiva, puede dar ciertos resultados en la determinación del estatus del liberto municipal.

Veamos unos textos que examinan en qué manera la comunidad y sus ciudadanos trataban al esclavo público o al liberto público:

Municipes per se nihil possidere possunt, quia universi consentire non possunt. Forum autem et basilicam hisque similia non possident, sed promiscue his utuntur. Sed Nerva filius ait, per servum quae peculiariter adquisierint et possidere et usucapere posse: sed quidam contra putant, quoniam ipsos servos non possideant. ${ }^{36}$

De la imposibilidad de poseer colectivamente los bienes públicos formulada por Paulo se sigue que el esclavo público pertenece al municipio y no a los munícipes. Paulo opina que el trato que los munícipes dan a los esclavos públicos es igual al de las construcciones municipales (basílicas, foros, etc.). La opinión particular de Nerva-hijo la veremos un poco más tarde.

Examinemos ahora la opinión de Ulpiano sobre las relaciones entre el liberto publico, y la comunidad y sus ciudadanos, que encontramos en el título De in ius vocando:

Qui manumittitur a corpore aliquo vel collegio vel civitate, singulos in ius vocabit: nam non est illorum libertus. Sed rei publicae honorem habere debet et si adversus rem publicam vel universitatem velit experiri, veniam edicti petere debet, quamvis actorem eorum constitutum in ius sit vocaturus. ${ }^{37}$

En este caso el jurista analiza si el manumitido por un collegium o una civitas puede litigar contra sus conciudadanos y su comunidad, que le manumitió. En este fragmento hay varios aspectos que merecen atención.

Como vemos, la comunidad, una civitas que concede la libertad a su esclavo, se define como un corpus (qui manumittitur a corpore aliquo). De esto prosigue que el colectivo que manumite a su esclavo se concibe como un organismo que actúa como una persona jurídica, dispone por sí misma de sus bienes, y en este caso, de su propio esclavo.

Cuando Ulpiano dice que el esclavo público manumitido puede litigar contra cualquier miembro de su civitas (singulos in ius vocabit), lo argumenta con lo siguiente: tal liberto no es de los esclavos privados (nam non est illorum libertus).

Detengámonos en estas palabras. El liberto no es un ex esclavo privado, por consiguiente ninguno de los ciudadanos de esta comunidad puede ser su patrono. Vemos que el liberto puede litigar contra cualquier miembro de su comunidad y que no tiene obligaciones ante ningún ciudadano personalmente, obligaciones que tiene normalmente el liberto manumitido de esclavos privados.

\footnotetext{
Halkin 1897, 142.

Dig. 41.2.1.22 (Paul. 54. ed.).

Dig. 2.4.10.4 (Ulp. 10. ed.).
} 
En este sentido se iguala a todos los miembros de la civitas. Su condición de persona libre se la debe solo a la propia res publica, a la que debe dar honores correspondientes (sed rei publicae honorem habere debet). Este liberto no tiene ninguna restricción a la hora de presentar demandas o litigar, a excepción de los litigios que van contra la propia comunidad (adversus rem publicam vel universitatem).

El poder de presentar demandas contra cualquier ciudadano de la comunidad, en nuestra opinión, puede ser otorgado solo a tal liberto que después de la manumisión se hace ciudadano del colectivo.

Como hemos dicho antes, la comunidad -en nuestro caso el municipio- es un cuerpo u organismo (corpus), él mismo manumite a su propio esclavo. Si la comunidad tiene el estatus de municipio, puede conceder la libertad a su esclavo sólo otorgándole el estatus del que gozan todos sus miembros de pleno derecho, es decir conceder la libertad junto con la condición de munícipe.

Así y todo, el texto analizado nos sugiere que el esclavo manumitido por el municipio no tiene patrono cierto (certus) porque su protector verdadero es el municipio, que según la definición de Ulpiano es un corpus incertum..$^{38}$ Es decir no hay nadie que pueda defender los intereses de tal liberto y él mismo necesita hacerlo sin esperar ayuda de su patrono incierto.

De esta forma la comunidad que tiene el estatus de municipio engendra en su seno un nuevo ciudadano, que en virtud del estatus municipal de su civitas puede ser solamente munícipe.

Por otra parte, el nacimiento inevitable de un nuevo ciudadano del liberto está condicionado por la naturaleza misma del patrono que realmente no puede ser protector de su propio liberto.

Parece que para entender por qué en una persona se juntan dos estatus que son desde el punto de vista habitual mutuamente excluyentes -Latinus y municeps- hay que tener en cuenta dos condiciones antes formuladas: primero, que el magistrado encargado de administrar justicia y pronunciar sentencias no puede emplear la vindicta durante la manumisión del esclavo público y, segundo, que el posesor real del esclavo público es el municipio y no los munícipes.

\section{Hereditas y bonorum possessio del munícipe-latino juniano}

Mientras tanto queda abierta la cuestión de la posibilidad de enajenación de hereditas que tenía el esclavo público tras la manumisión.

Andrew Fear notó que según la ley Irnitana los libertos municipales tenían derecho a disponer de su herencia (hereditas), que era un rasgo característico de una persona libre y no de un latino juniano, cuyos bienes, después de su muerte, pasaban en pleno a su ex dueño. ${ }^{39}$ Basándose en este argumento este autor concluyó que tales libertos no eran latinos junianos y por lo tanto eran libres, mientras que el estatus de Latinus estaba ligado con el ius Latii, del cual gozaban todos los munícipes. ${ }^{40}$

De igual manera, el hecho de que los libertos municipales tuviesen hereditas sirvió de prueba a Heidrun Schulze-Oben de que la manumisión se efectuaba por vin-

\footnotetext{
Ulp. 22.5.

Gai. Inst. 3.56 .

Fear 1996, 137.
} 
dicta, debido a lo cual los esclavos públicos recibían el estatus del latino y eran beneficiarios del ius Latii. ${ }^{41}$

El concepto de hereditas, al cual los investigadores apelan como a un hecho indiscutible que prueba la equivalencia de condición de los Latini y de los munícipes con ius Latii-Latinus y municeps-, está incorporado en la frase: (...) inque eius qui ita manumissus manumissave erit hereditate bonorum possessione petenda operis dono munere idem ius municipii Flavi Irnitani esto (...).

En esta prescripción, que sienta las bases de las relaciones de propiedad entre el liberto y la comunidad-patrono, se dice que el municipio tiene derecho a ejercer la petición de herencia y a la posesión de los bienes hereditarios de su liberto, así como a demandar sus operae, dona et munera.

Antes hemos señalado que el patrono del liberto de los esclavos públicos es su comunidad (universitas, res publica), y no los munícipes. Por lo tanto, las obligaciones que el liberto tenía ante su patrono, no las cumplía respecto a los munícipes por separado, sino respecto al municipio. La comunidad, como hemos visto, según los juristas es un cuerpo único, un organismo único (corpus). Y si este organismo tenía derecho a usar su posesión -sus esclavos-a su albedrío y actúa como patrono de su liberto, inevitablemente se impone la cuestión de si el municipio puede actuar como el heredero de su liberto después de su muerte.

En teoría precisamente la comunidad debe ser heredera de su liberto, tanto más si él es latino juniano. Sin embargo la comunidad como patrono tiene sus peculiaridades que la distinguen de una persona privada en lo que se refiere a la herencia, y es lo que señala Ulpiano:

Nec municipia nec municipes heredes institui possunt, quoniam incertum corpus est, et neque cernere universi neque pro herede gerere possunt, ut heredes fiant: senatus consulto tamen concessum est, ut a libertis suis heredes institui possint. Sed fideicommissaria hereditas municipibus restitui potest; denique hoc senatus consulto prospectum est. ${ }^{42}$

En este caso el jurista examina si el municipio puede ser heredero de su liberto. Como hemos dicho antes, Ulpiano declara que cada civitas y cada collegium es corpus, es decir cuerpo u organismo. ${ }^{43}$ En este caso el jurista precisa que el municipio es un corpus incertum, es decir es un organismo indefinido, que se presenta como un conjunto de los munícipes.

En este razonamiento de Ulpiano, así como en el texto de Paulo antes citado, hallamos un pensamiento común para los dos: los munícipes todos juntos (universi) no pueden poseer ninguna cosa por sí mismos (municipes per se nihil possidere possunt),${ }^{44}$ ni ser instituidos herederos (nec municipes heredes institui possunt) ${ }^{45}$ Dicho con otras palabras, los munícipes no pueden ser dueños colectivos ni herederos colectivos. Ambas limitaciones derivan de la imposibilidad de manifestar una voluntad colectiva.

\footnotetext{
41 Schulze-Oben 1989, 42 y 47.

42 Ulp. 22.5.

43 Dig. 2.4.10.4.

$44 \quad$ Dig. 41.2.1.22.

45 Ulp. 22.5 .
} 
Paulo afirma que los munícipes no poseen esclavos públicos porque en general no pueden poseer nada en virtud de que todos los munícipes no pueden estar de acuerdo: universi consentire non possunt. Cada munícipe tiene su propio interés en relación con cualquier cosa y este interés puede entrar en contradicción con los intereses de sus conciudadanos. Con esto el jurista subraya que el único dueño de este esclavo es el municipio. El esclavo público, como una basílica o un foro, es una cosa que pertenece al municipio, los munícipes pueden usarla, pero no la poseen: ipsos servos non possideant. Lo único que se puede hacer sin causar daño a los intereses del municipio es manumitirlo; sin embargo, también en este caso el manumissor de todas maneras será el municipio y no los munícipes. Y cuando este esclavo se hace liberto se queda en el seno de su municipio obligado a ejecutar los cargos y las obras en provecho del propio municipio, su patrono, y no en el de los munícipes.

La discrepancia que hay entre Paulo y Nerva (sed Nerva filius ait, per servum quae peculiariter adquisierint et possidere et usucapere posse $)^{46}$ consiste en que el último admite la posibilidad de adquirir algo a través del esclavo público por la posesión o por la usucapión, usando peculio. Así Nerva iguala el esclavo municipal al esclavo privado. Sin embargo, según Paulo la posesión del municipio de esclavos públicos absolutamente se distinguía de la posesión de los esclavos por los ciudadanos precisamente en virtud de la imposibilidad de la posesión colectiva.

Cuando Ulpiano sostiene que ni el municipio ni los munícipes pueden ser nombrados como herederos, se guía por consideraciones similares: el municipio como el conjunto de los munícipes es un organismo indefinido (incertum corpus est), y los munícipes no pueden ser herederos, porque por la imposibilidad de la voluntad colectiva todos juntos no pueden ni adir la herencia, ni proceder como un heredero: neque cernere universi neque pro herede gerere possunt.$^{47}$

A continuación Ulpiano pasa a otro razonamiento y dice, que según un senadoconsulto el municipio puede ser designado heredero por sus libertos: senatus consulto tamen concessum est, ut a libertis suis heredes institui possint. ${ }^{48}$

Entre dos partes de la frase hay una relación directa. La esencia del problema se basa en lo siguiente: el municipio como patrono tiene derecho a reclamar la parte legal de la herencia de su liberto (en caso de latino juniano tiene derecho a reclamar todos los bienes de su liberto), pero no puede ser nombrado heredero en virtud de la regla general. Es probable que antes de ser aprobado el senadoconsulto esta cuestión fuera regulada por el fideicomiso universal, del que se trata en el fragmento de Ulpiano: sed fideicommissaria hereditas municipibus restitui potest. ${ }^{49}$

Los intereses de la comunidad que es patrona del liberto municipal estaban bajo una segura protección jurídica en la esfera de sucesión mortis causa, como se comprueba tanto en la rúbrica 72 como en el texto de Ulpiano, que da importantes recomendaciones sobre las vías que tenía el municipio para llegar a ser heredero de su liberto.

El derecho del municipio a reivindicar hereditas y bonorum possessio de su liberto, establecido en la rúbrica 72 de la Lex Irnitana presupone que este liberto municipal tenía el derecho a disponer de sus bienes mortis causa, es decir redactar el testa-

\footnotetext{
$46 \quad$ Dig. 41.2.1.22 (Paul. 54 ed.).

$47 \quad$ Ulp. 22.5 .

48 Ulp. 22.5.

49 Ulp. 22.5.
} 
mento, lo que contradice al estatus de latino juniano, pero no al estatus del ciudadano del municipio. Es probable que hereditas y bonorum possessio fuesen puro formulismo para los libertos municipales a diferencia de los latinos junianos ordinarios, para quienes estas instituciones eran excluidas completamente.

\section{6. ¿Por qué la manumisión del servus publicus se realiza sin vindicta?}

Volvamos al inicio del fragmento de Ulpiano donde se dice que el municipio no puede ser heredero: Nec municipia nec municipes heredes institui possunt, quoniam incertum corpus est, et neque cernere universi neque pro herede gerere possunt, ut heredes fiant. ${ }^{50}$

Este razonamiento tiene un valor decisivo para comprender por qué el esclavo municipal se manumite no como un liberto de pleno derecho sino como un latino juniano. Según Ulpiano, ni los munícipes ni el municipio pueden ser nombrados herederos porque, por un lado, el municipio es un cuerpo incierto y, por otro, los munícipes no pueden todos juntos entrar en una herencia.

Parece que, por analogía, el municipio no puede actuar en función de un dueño que concede la libertad a su esclavo. El municipio, siendo corpus incertum, no puede él mismo hacer una concesión de libertad o una manumisión; al mismo tiempo el esclavo público no es posesión de cada munícipe por separado; por lo tanto los munícipes no pueden concedérsela por vindicta.

Otra constitución de Diocleciano y Maximiano puede servir de argumento complementario de esta interpretación. En ella se dice lo siguiente: Nihil civitati Romanae semel praestitae vel addere vel detrahere secundam manumissionem potuisse certissimum est. ${ }^{51}$

Esta opinión, por lo visto, servía de respuesta a la pregunta de si era posible una manumisión por vindicta repetitiva. Según este rescripto se ve que una vez realizada, la manumisión por vindicta ya atribuía la ciudadanía romana y que su realización repetitiva carecía de sentido. De ahí se infiere que la manumisión por vindicta se podía utilizar solo una vez y solo por una persona privada, y no por varias personas. Manumisión vindicta, así como el derecho a heredar podían realizarse solamente en las situaciones cuando los ciudadanos los utilizaban personalmente en sus casos privados.

Manumisión vindicta fue un poder exclusivo del civis Romanus, que él podía ejecutar solamente en el momento de dar libertad a su propio esclavo.

Ningún munícipe podía manumitir vindicta a un servus publicus, porque no era su propio esclavo sino del municipio.

\section{Conclusión}

Hemos intentado aquí reconstruir, partiendo de las fuentes legales, el estatus personal y legal del liberto municipal. Todas estas fuentes, independientemente una de la otra, indican que solamente la comunidad -el municipio-, y no sus ciudadanos, era

Ulp. 22.5 .

C.Iust. 7.1.2. 
posesora del liberto público. La naturaleza específica de la comunidad como posesora y patrona -corpus incertum - imponía sus particularidades a la manumisión del servus publicus y el futuro estatus del liberto municipal.

Tal liberto no estaba obligado por su manumisión a ningún munícipe en persona, sino a su municipio.

El servus publicus no era posesión personal de los munícipes y por eso no podía ser manumitido vindicta. La manumisión vindicta era una forma de dar libertad a los esclavos privados que pertenecían a los cives Romani y no a las personas privadas de cualquier otra condición. Aprovecharse de este derecho era algo que sólo podía hacer un ciudadano romano y no el colectivo de ciudadanos o su magistrado. Las relaciones entre los libertos municipales y los munícipes no eran iguales a las relaciones que existían entre los libertos latinos junianos de los esclavos privados y sus patronos.

Las relaciones "liberto - patrono" se establecían solamente con el municipio, y esto es precisamente lo que dice la ley municipal Irnitana: que el municipio tenga el derecho -ius municipii Flavi Irnitani sunto- de ejercer la petición de herencia y la posesión de los bienes hereditarios -in (...) eius (...) hereditate bonorum possessione petenda-. Para los munícipes el liberto público era un munícipe que tenía, como todos sus conciudadanos, el poder de petición de herencia (hereditas) y el de posesión de los bienes hereditarios (bonorum possessio); para el municipio era un liberto latino juniano, cuyos bienes el municipio como patrono podía pretender después de su muerte, así como sus operae, dona et munera, mientras viviera.

\section{Referencias bibliográficas}

Braunert, H. (1966): “Ius Latii in den Stadtrechten von Salpensa und Malaca”, [en] Corolla Memoriae Erich Swoboda dedicata, Graz-Köln, 68-83.

Chastagnol, A. (1995): “Coloni et incolae. Note sur les différenciations sociales à l'intérieur des colonies Romaines de peuplement dans les provinces de l'Occident. (Ier s. av. J.-C. - Ier s. ap. J.-C.)", [en] A. Chastagnol, La Gaule Romaine et le droit Latin. Recherches sur l'histoire administrative et sur la romanisation des habitants (Scripta varia 3), (=Collection du Centre d'Études Romaines et Gallo-romaines 14), Lyon, 131-141.

D’Ors, A. (1986): La ley Flavia municipal (texto y comentario), (=Pontificium Institutum Utriusque Iuris. Studia et documenta 7), Roma.

Eder, W. (1980): Servitus publica. Untersuchungen zur Entstehung, Entwicklung und Funktion der öffentlichen Sklaverei in Rom, Wiesbaden.

Fear, A. T.

(1990): “Cives Latini, servi publici and the Lex Irnitana”, RIDA 37, 149-167.

(1996): Rome and Baetica. Urbanization in Southern Spain c. 50 BC-AD 150, Oxford.

Galsterer, H. (1971): Untersuchungen zum römischen Städtewesen auf der iberischen Halbinsel, Berlin

Gardner, J. F. (2001): "Making Citizens: the Operation of the Lex Irnitana", [en] Administration, Prosopography and Appointment Policies in the Roman Empire. Proceedings of the First Workshop of the International Network Impact of Empire (Roman Empire, 27 B.C. - A.D. 406), Leiden, June 28 - July 1, 2000 (=Impact of Empire 1), Amsterdam, 215-229.

Giménez-Candela, T. (1981): "Una contribución al estudio de la ley Irnitana: la manumisión de esclavos municipales", IURA 37, 37-56. 
González Fernández, J. - Crawford, M. (1986): “The Lex Irnitana: a new copy of the Flavian municipal law", JRS 76, 147-243 (https://doi.org/10.3815/007543508786239535).

Halkin, L. (1897): Les esclaves publics chez les Romains, Bruxelles.

Humbert, M. (1981): “Le droit latin imperial: cites latines ou citoyenneté latine?", Ktéma 6, 207-226.

Kränzlein, A. (1991): "Statuswechsel nach der lex Irnitana", [en] Tradition und Fortentwicklung im Recht. Festschrift von Lübtow, Berlin, 45-51.

Lebek, W. D. (1995): "Die municipalen Curien oder Domitian als Republikaner: Lex Lati (Tab. Irn.) Paragraph 50 (?) und 51”, ZPE 107, 135-194.

Le Roux, P. (1986): "Municipe et droit latin en Hispania sous l'Empire", RHD 64/3, 325-350. (1991): "Municipium Latinum et Municipium Italiae: à propos de la Lex Irnitana", [en] Epigrafia. Actes du Colloque international en mémoire de Attilio Degrassi. Rome, 27-28 mai 1988 (=Collection de l'École française de Rome 143) Rome, 565-582. (1998): "Rome et le droit latin", RHD 76/3, 315-341.

López Barja de Quiroga, P. (1991): “Latini y Latini Iuniani. De nuevo sobre Irn. 72”, SHHA 9, 51-60.

Millar, F. G. B. (1992)2: The Emperor in the Roman World (with a new afterword by the author), London.

Mommsen, Th.

(1887): Römisches Staatsrecht. 3/1, Leipzig.

(1905): "Die Stadtrechte der latinischen Gemeinden Salpensa und Malaca in der Provinz Baetica", [en] Gesammelte Schriften.1, Berlin, 265-382.

Schulze-Oben, H. (1989): Freigelassene in den Städten des römischen Hispanien. Juristische, wirtschaftliche und soziale Stellung nach dem Zeugnis der Inschriften, Bonn.

Sudi-Guiral, F. (2013): Les esclaves et les affranchis publics dans l'Occident romain II' siècle avant J.-C. - III' siècle après J.-C., Paris.

Wolff, H. (1976): "Die cohors II Tungrorum milliaria equitata c(oram?) 1(audata?) und die Rechtsform des ius Latii”, Chiron 6, 267-288. 
